\title{
The Attitudes of Pulmonologists Regarding Smoking Behavior of Their Patients with Advanced COPD: A Qualitative Research
}

This article was published in the following Dove Press journal: International Journal of Chronic Obstructive Pulmonary Disease

\author{
K Mooren (iD) ${ }^{1, *}$ \\ GGH van der Linden $\mathbb{I D}^{2, *}$ \\ $\mathrm{KPool}^{3}$ \\ Y Engels ${ }^{4}$
}

'Department of Lung Disease, Spaarne Gasthuis, Haarlem, Noord-Holland, the Netherlands; ${ }^{2}$ Department of Internal Medicine, ETZ, Tilburg, Noord-Brabant, the Netherlands; ${ }^{3}$ Department of Lung Disease, Rode Kruis Ziekenhuis, Beverwijk, Noord-Holland, the Netherlands; ${ }^{4}$ Department of Anaesthesiology, Pain and Palliative Care, RadboudUMC, Nijmegen, Gelderland, the Netherlands

*These authors contributed equally to this work
Correspondence: K Mooren

Department of Lung Disease, Spaarne

Gasthuis, Boerhaavelaan 22, Haarlem

2035RC, Noord-Holland, the

Netherlands

$\mathrm{Tel}+31624419288$

Email k.mooren@spaarnegasthuis.nl
Background: Patients with diseases linked with smoking, such as COPD, report a healthrelated stigma on their smoking behavior, which is related to a poorer quality of life and psychological distress. According to patients with COPD, health-care professionals sometimes reinforce the sense of stigma. However, little is known about the physicians' attitudes on this topic towards the patient with COPD.

Purpose: To explore attitudes of pulmonologists regarding the smoking behavior of their patients with COPD and if (and to what extent) a stigma is present in their attitudes towards their smoking patients.

Patients and methods: Eighteen pulmonologists were interviewed using a semi-structured guide with prespecified topics. The interview transcripts were coded using Atlas.ti. Analysis of data from these interviews was performed using conventional content analysis.

Results: We identified three themes: attitudes towards smoking in general, the interaction between patient and physician, and smoking cessation. All participants said patients are not fully responsible for their smoking behavior. Contrarily, smoking was also seen as a free choice by most physicians. Moreover, smoking cessation was mostly seen as the responsibility of the patient. Feelings of powerlessness, frustration and compassion were reported in the guidance of patients with COPD.

Conclusion: The results of this study show an ambivalent attitude of pulmonologists regarding the smoking behavior of their patients with COPD. The outcomes of this study can form a base for further research and can be used as insights for interventions that aim to raise awareness of physicians' own attitudes and increase the quality of physician-patient communication.

Keywords: COPD, patient-physician interaction, physician attitudes, qualitative research, smoking

\section{Introduction}

Chronic obstructive pulmonary disease (COPD) is one of the most common chronic respiratory diseases. It affects about $3 \%$ of the population worldwide and is responsible for over 3 million deaths annually. ${ }^{1}$ The burden of disease is high, due to the increasing prevalence and progressive disease course, which is characterized by exacerbations. ${ }^{1,2}$ The WHO predicts that COPD will be the third leading cause of death worldwide in $2030 .^{3}$

Cigarette smoking is the most important risk factor of COPD. The lifetime risk for smokers of getting COPD is estimated to be over $20 \%{ }^{4}$ Cessation of smoking is beneficial since it improves survival in patients with COPD and improves the 
quality of life by many positive physiological and psychological effects. ${ }^{4-6}$ However, smoking tobacco is extremely addictive, ${ }^{7}$ and the use of tobacco is strongly influenced by industry marketing. ${ }^{8}$ Tobacco marketing targets youth, seducing millions of teenagers to experiment with tobacco. ${ }^{8-10}$

Patients with diseases linked to smoking, including COPD, frequently perceive a health-related stigma. ${ }^{11-15}$ In patients with COPD, the stigma on their smoking behavior has a strong emotional impact, regardless of their smoking status. ${ }^{12}$ A large part of the population regards smoking as a choice instead of an addiction. Consequently, having COPD is seen as a personal responsibility. ${ }^{11,16}$ This blaming attitude makes patients feel stigmatized, which causes feelings of guilt and shame. ${ }^{11,13}$ Many patients experience little sympathy because COPD is regarded as a self-inflicted disease. ${ }^{17}$ This may lead to isolation, loss of self-esteem, feelings of uselessness and even depression and anxiety. ${ }^{11,14,18}$

The sense of stigma and self-blame of patients with COPD can be reinforced by attitudes of health-care professionals. ${ }^{14}$ Perceptions about the role of smoking in COPD differ between physicians and patients, with physicians seeing smoking as the leading cause of most cases of COPD, whilst patients often have different views. ${ }^{19}$ Some patients with COPD believe that health-care professionals are biased against them because of their tobacco addiction. ${ }^{20}$ This may lead to patients not being completely frank to their physician, a delay in seeking care, and even a decrease in medication adherence. ${ }^{20,21}$

Most studies performed on this topic have focused on patients' perspectives. One study used focus groups to explore the experiences of smokers with COPD and of physicians on smoking cessation in COPD. This study addressed three themes that hindered cessation: frustration in physicians, negative beliefs and lack of knowledge regarding cessation treatment, and health-care organizational factors. ${ }^{22}$ Another study, using narrative medicine, found that pulmonologists often described their doctor-patient relationship as difficult, in cases where the patient continued to smoke. ${ }^{23}$

The aim of the current study was to explore the attitudes and behavior of pulmonologists in the Netherlands regarding the smoking behavior of patients with COPD.

\section{Materials and Methods}

\section{Study Design}

To explore attitudes of pulmonologists regarding the smoking behavior of their patients with COPD, a qualitative design was used with in-depth semi-structured interviews. In the Netherlands, no medical ethical permission is required for interviewing health-care professionals, unless it concerns sensitive topics.

To guide the interviews, a topic list was developed. The initial topic list was constructed using knowledge from the existing literature on attitudes of professional caregivers regarding smoking-related behavior and stigma, and discussions between authors KM, YE and KP, who have specific knowledge on palliative care, spiritual health care and smoking addiction in COPD. These main topics were (1) attitudes regarding smoking in general and (2) attitudes regarding smoking behavior of patients with COPD (See Appendix). If new topics emerged based on the obtained information from the first interviews, they were added to the topic list. All interviews were conducted by one researcher (GvdL), who had not met the interviewees before. Each face-to-face interview took approximately half an hour and was conducted in the hospital where the participating pulmonologist practiced. Openended key questions were used. After no new concepts were found, three additional interviews were performed to guarantee data saturation. For this reason, the sample size was not predetermined.

\section{Participants}

Pulmonologists, in most cases being the primary caregiver of patients with COPD next to general practitioners, were interviewed. Pulmonologists who worked in the three hospitals chosen for this study received an email with the invitation to participate. In two hospitals, pulmonologists work in partnerships and are therefore not employed by the hospital. In the third (academic) hospital, permission to contact the pulmonologists was obtained by the head of the department. Interviewees were registered pulmonologists in the Netherlands and not specialized in palliative care or smoking cessation. Purposive sampling was done to include both male and female pulmonologists, having different lengths of working experience, and working in different hospitals. Prior to each interview initiation, informed consent was obtained from the participants; consent to be in the study and for anonymous quotes to be used was given.

\section{Data Analysis}

The interviews were audio-recorded and transcribed verbatim. The transcripts were returned to the participants for comments or corrections. Three researchers (a pulmonologist, KM, 
a medical student in the final year of his master GvdL, a professor in spiritual health care, YE) independently open coded the first five interviews line by line with direct content analysis and compared and discussed the codes until consensus was reached on the code book. The remaining interviews were coded by one researcher (GvdL). During a meeting of two researchers (GvdL, YE), similar codes were merged. This coding process was performed using Atlas.ti software v.8 (http://atlasti.com; Atlas.ti Scientific Software Development $\mathrm{GmbH}$, Berlin, Germany). Next, two researchers (GvdL, YE) grouped the codes into themes and sub-themes to get an overview of all mentioned determinants.

\section{Results}

A total of 18 pulmonologists were interviewed, of whom 12 were women $(67 \%)$. The age of the participants was between 35 and 63 years and they had 1 to 27 years of working experience as a pulmonologist. The interviews were held in three different hospitals in the Netherlands: one academic hospital and two large teaching hospitals. Saturation was reached after 15 pulmonologists had been interviewed. The initial number of 99 codes could be merged into 20 codes. These could be grouped into six categories. Out of these categories, we identified three themes: (1) attitudes towards smoking in general, (2) interaction between patient and physician, and (3) attitudes towards smoking cessation.

\section{Attitudes Towards Smoking in General Public Health}

Almost all pulmonologists thought of tobacco as something negative and most of them stated that smoking needs to be banished. The participants reported different strategies to reduce smoking in society, such as increasing taxes or more laws on prohibiting smoking. The majority thought that the government acts too little on prevention and should protect its citizens.

Of course, there's a very double interest, so partially it is for the state budget: it produces a lot. If people massively quit smoking, they live longer, so the pensions do not check out as well. So, it is discouraged, but it should all be a little firmer.

Several participants recommended a change in funding on prevention and cessation of smoking from health-care insurance companies, and to tackle the tobacco industry. Some pulmonologists said that physicians do not take enough responsibility in helping their patients to quit smoking.

\section{Responsibility}

Most of the interviewees said it is hard to name one single party that can be held responsible for the smoking problem. All interviewees said that people are not or not fully responsible for their smoking behavior.

A part is the mechanism of addiction; people often started at young age, indoctrinated by advertisements or herd behavior. To what extent can you still blame them now?

However, most of them saw smoking also as a free choice or held smokers at least partially responsible for it. Besides, almost all pulmonologists reported the tobacco industry or the government to be responsible. Half of the interviewees stated that society in general or the social environment of smokers are responsible.

\section{Interaction Between Patient and Physician Feelings of Physicians}

Regarding patients with COPD who keep smoking, participants reported experiencing different feelings. The majority reported feelings of powerlessness, although some of them said that they developed a feeling of acceptance over time. Most participants reported feelings of frustration regarding the continuation of smoking.

What you can say is: you must not moan about your COPD if you continue to smoke. Then I will not moan about smoking and you will not moan about your complaints.

However, an equal number of participants reported compassion with smoking patients with COPD. A minority of the interviewed pulmonologists experience pride towards patients who managed to quit smoking, and a few said that they have the same approach to smokers and non-smokers. Several participants stated that their own attitude towards the smoking behavior of their patients had become more understanding over time.

\section{Role of Physicians}

The majority of the participants stated that pulmonologists should always support patients with COPD, regardless of their smoking state. On the other side, more than half of the pulmonologists had doubts about the usefulness of treatment and a minority of the pulmonologists reported feeling useless as a physician when a patient with COPD continues to smoke.

I admit someone on the ward with an exacerbation of COPD.

I admit him on a Saturday. I am doing the rounds on a Sunday, the nurse comes: "yes, he is downstairs smoking a cigarette." 
Then I think: you know, if you can smoke a cigarette during an exacerbation, then you might as well go home.

\section{Patient Perspective}

Almost all participants recognized shame and feelings of guilt in a part of their patients with COPD.

"Yes doctor, I have to admit something to you." They use that a lot the word "to admit"; that says something about how they feel about it. As if they owe me accountability.

Most participants make an effort to take these feelings away. A few participants stated that only a minority of the COPD patients experience guilt and shame. A small group of physicians also noticed that some patients suffer from the blaming society and their social environment. Half of the interviewees observe that, as a consequence of the experienced shame and guilt, patients are not completely honest to the pulmonologists about their smoking behavior.

\section{Smoking Cessation}

For smoking cessation guidance, almost all participants refer patients to the general practitioner or a specialized smoking cessation clinic. More than half of the participants said that it is practically impossible for pulmonologists to guide patients in smoking cessation themselves. However, the majority reported they discuss smoking cessation in every contact with their patients with COPD. Most participants tend to discuss the disadvantages of continuing more than the benefits of quitting. They reported to avoid being too harsh in their approach in order to maintain the therapeutic relationship. Some participants reported they use a stricter approach towards patients on smoking cessation, for example, threatening with ending treatment in the hospital.

I am a little stricter. For example: I admit a patient with an exacerbation of COPD to the hospital. The next day I hear the nurse say: "the patient is downstairs to smoke a cigarette". In that case I think: if you can go downstairs to smoke a cigarette, then you might as well go home.

Nearly every participant stated that the patient has his or her own responsibility in smoking cessation; two participants called it a choice not to quit smoking. Several participants reported that it is useless for a health-care professional to put an effort into smoking cessation if a patient does not make an effort as well.

If it's purely externalizing, if I can put it like this, that they say: "solve it doctor. I'm getting sicker, but too bad! And you have to give me something which makes me feel better." Then I try to make them aware that it does not work this way.

Half of the participants acknowledged that quitting tobacco use is very difficult for the patient and a few participants recognized feelings of fear and frustration in patients, who want to quit smoking but do not succeed. Furthermore, the social environment of the patient was mentioned multiple times. Several interviewed pulmonologists reported they often see family and friends putting pressure on the patient to quit smoking, whilst a few reported the social environment to be the main reason patients cannot quit smoking.

I always try to take away the blaming part. Often you see families pushing to quit smoking in terms of: "why you just don't quit?" You want to prevent that. You want support, not punishment for their behavior.

\section{Discussion}

We identified three major themes regarding their attitudes towards smoking: attitudes towards smoking in general, smoking cessation, and the interaction between patient and physician.

This study showed that all interviewed pulmonologists agreed that patients cannot be fully held responsible for their smoking behavior. This was mostly because smoking was (correctly) seen as a strong addiction. ${ }^{24}$ At the same time, smoking was also regarded as a choice by the majority of the participants. In other words, the respondents had contradictory views: almost all of them stated that patients are not fully responsible, and, on the other hand, thought that patients have their own responsibility in smoking cessation.

Most participants did not hold one single stakeholder responsible. Besides the tobacco industry, the government, the social environment and society, in general, were mentioned to play a role in smoking addiction. Indeed, having friends who smoke, low parental support, pro-smoking attitudes and low socio-economic status have been shown to be important factors predicting the initiation of smoking. ${ }^{25}$ Heritability of higher susceptibility to nicotine dependence was also mentioned. ${ }^{26}$ When asking for the best strategy to stop smoking on societal level, most participants pointed out that the government acts too little on prevention. Regarding smoking cessation for the individual patient, most pulmonologists in our study refer patients to their general practitioner. 
In the Netherlands, general practitioners use a guideline, containing effective interventions for smoking cessation. ${ }^{27}$

An interesting finding in our study is that almost every participant mentions smoking cessation during every contact with their patients, although they believe the advice is futile if the patient does not have the motivation to quit smoking. This belief, however, is not correct; randomized controlled trials showed that a brief advice from a physician to stop smoking increases the rate of quitting of all who receive it, whether or not they were motivated to quit. ${ }^{30}$ The offer to support them appears to be more effective than just the advice to stop. ${ }^{25,31}$ This suggests that pulmonologists do not realize that they can manage to empower the intrinsic motivation to quit in patients with only a minor intervention. The majority of the interviewed pulmonologists said they do not want to be too strict towards their patients, as they want to maintain the therapeutic relationship. This confirms the findings of a previous study that found that smokers with COPD are open to receive help and support but do not want to be patronized. ${ }^{32}$ Some patient-centered styles of counseling, like motivational interviewing, can be useful and will enhance the therapeutic relationship without patronizing. ${ }^{33}$

Regarding the doctor-patient relationship, most interviewed pulmonologists reported feelings of powerlessness, followed by frustration and compassion concerning the smoking behavior of their patients. This is in line with findings of previous studies on perceptions of patients with COPD on physicians' attitudes: some patients reported being ridiculed or criticized, while others felt fully accepted and supported by their physician. ${ }^{14}$ In our study, taking care of patients who have no motivation to quit smoking, was most frequently mentioned as a source for feelings of powerlessness and frustration. It appeared that physicians do not always understand this "lack of motivation", although several explanations have been described in the literature. ${ }^{28}$ Smokers with COPD report that in their vision of life, smoking cessation is not a priority. They are less knowledgeable about the health consequences of smoking and have little faith in the efficacy of smoking cessation aids. ${ }^{28,29}$ On the other hand, patients perceive a lack of empathy from doctors and state that advice on smoking would have a more encouraging effect if there was more empathy reflected in the communication. ${ }^{28}$ Most patients with COPD experience stigmatization and a lack of support from their social network, society and health-care professionals, due to their (history of) smoking behavior. ${ }^{11,12,14,15}$ The notion that compassion from the physician with the smoking COPD patient might well be a key element in maintaining a positive doctor-patient relationship, and perhaps even in motivating the patient to stop smoking, has previously been suggested by the study of Banfi et al. ${ }^{23}$ When using a narrative tool, prompting professionals to reflect on their own emotions in treating COPD patients, they found that pulmonologists who were able to overcome their initial discomfort, and listen to the patient, were more likely to find a strategy to encourage the patient to end their dependence. In our study, almost all participants recognized feelings of blame and shame in their patients, but they did not always attempt to reduce such feelings. According to these findings, communication training for pulmonologists should comprise three key elements:

1. Awareness of the "knowledge gap" between physicians and patients on the effects of smoking cessation.

2. Recognition of feelings of shame and blame, and making an effort to reduce these feelings.

3. Compassion with the COPD patient, who experiences a high burden of disease, partially caused by a smoking addiction.

\section{Strengths and Limitations}

To our knowledge, this study is the first study that explored the attitudes of physicians towards smoking behavior in patients with COPD using one-on-one interviews. These insights are important since patients with COPD should experience compassion from their pulmonologist when smoking addiction is addressed, whilst the success rate of their attempts to quit smoking should be maximized.

Our study has some limitations. Possibly, the pulmonologists gave socially desirable answers to the interviewer, expressing themselves more mildly than they actually feel. For assessment of the generalizability of our findings, the local cultural influences and regulations on tobacco must be kept in mind. Furthermore, the interviews were held in a period in which the problem around smoking and the tobacco industry received ample attention in the Dutch media. This was caused by a lawsuit against the tobacco industry for adding additives to make cigarettes more addictive, in order to get existing smokers to keep smoking and to get starting smokers addicted to cigarettes more quickly. ${ }^{34}$ This may have influenced the views of the participants. Lastly, we only interviewed pulmonologists; other health-care professionals involved in the care for patients with COPD such as general practitioners and nurses may have different attitudes. 


\section{Conclusion}

We found that pulmonologists in the Netherlands have an ambivalent attitude on smoking behavior in their patients with COPD. Many pulmonologists consider smoking a free choice and hold patients responsible for cessation, whilst on the other hand acknowledge the addictive nature of tobacco smoking. Pulmonologists who treat smoking COPD patients experience feelings of powerlessness and frustration, but also compassion. They recognize feelings of blame and shame in their patients but do not always act upon them.

\section{Acknowledgment}

We would like to acknowledge all of the pulmonologists who participated in the interviews.

\section{Disclosure}

The authors report no conflicts of interest in this work.

\section{References}

1. GBD 2015 Chronic Respiratory Disease Collaborators. Global, regional, and national deaths, prevalence, disability-adjusted life years, and years lived with disability for chronic obstructive pulmonary disease and asthma, 1990-2015: a systematic analysis for the Global Burden of Disease Study 2015. Lancet Respir Med. 2017;5 (9):691-706. doi:10.1016/S2213-2600(17)30293-X

2. Buist AS, McBurnie MA, Vollmer WM, et al. International variation in the prevalence of COPD (the BOLD Study): a population-based prevalence study. Lancet. 2007;370(9589):741-750. doi:10.1016/ S0140-6736(07)61377-4

3. WHO. Chronic Obstructive Pulmonary Disease (COPD); 2017. Available from: https://www.who.int/en/news-room/fact-sheets/detail/chronicobstructive-pulmonary-disease-(copd). Accessed December 2, 2018.

4. Løkke A, Lange P, Scharling H, Fabricius P, Vestbo J. Developing COPD: a 25 year follow up study of the general population. Thorax. 2006;61(11):935-939. doi:10.1136/thx.2006.062802

5. Berry CE, Wise RA. Mortality in COPD: causes, risk factors, and prevention. Copd. 2010;7(5):375-382. doi:10.3109/15412555.2010. 510160

6. Taylor G, McNeill A, Girling A, Farley A, Lindson-Hawley N, Aveyard P. Change in mental health after smoking cessation: systematic review and systematic review and meta-analysis. BMJ. 2014;348:g1151.

7. Sohn M, Hartley C, Froelicher ES, Benowitz NL. Tobacco use and dependence. Semin Oncol Nurs. 2003;19(4):250-260. doi:10.1053/j. soncn.2003.08.002

8. Eisenberg M, Ringwalt C, Driscoll D, Vallee M, Gullette G. Learning from truth: youth participation in field marketing techniques to counter tobacco advertising. J Health Commun. 2004;9(3):223-231. doi:10.1080/10810730490447066

9. Portnoy DB, Wu CC, Tworek C, Chen J, Borek N. Youth curiosity about cigarettes, smokeless tobacco, and cigars: prevalence and associations with advertising. Am J Prev Med. 2014;47(2 Suppl 1):S76S86. doi:10.1016/j.amepre.2014.04.012

10. Bates C, Rowell A. Tobacco explained ... The truth about the tobacco industry ... in its own words. London: action on Smoking and Health. 2004. Available from: www.who.int/tobacco/media/en/ TobaccoExplained.pdf.
11. Rose S, Paul C, Boyes A, Kelly B, Roach D. Stigma-related experiences in non-communicable respiratory diseases: a systematic review. Chron Respir Dis. 2017;14(3):199-216. doi:10.1177/1479972316680847

12. Svedsater H, Roberts J, Patel C, Macey J, Hilton E, Bradshaw L. Life impact and treatment preferences of individuals with asthma and chronic obstructive pulmonary disease: results from qualitative interviews and focus groups. Adv Ther. 2017;34(6):1466-1481. doi:10.1007/s12325-017-0557-0

13. Chambers SK, Dunn J, Occhipinti S, et al. A systematic review of the impact of stigma and nihilism on lung cancer outcomes. BMC Cancer. 2012;12:184. doi:10.1186/1471-2407-12-184

14. Berger BE, Kapella MC, Larson AL. The experience of stigma in chronic obstructive pulmonary disease. West J Nurs Res. 2011;33 (7):916-932. doi:10.1177/0193945910384602

15. Halding AG, Heggdal K, Wahl A. Experiences of self-blame and stigmatisation for self-infliction among individuals living with COPD. Scand J Caring Sci. 2011;25(1):100-107. doi:10.1111/ j.1471-6712.2010.00796.x

16. Marlow LA, Waller J, Wardle J. Variation in blame attributions across different cancer types. Cancer Epidemiol Biomarkers Prev. 2010;19 (7):1799-1805. doi:10.1158/1055-9965.EPI-09-1298

17. Stuber J, Galea S, Link BG. Smoking and the emergence of a stigmatized social status. Soc Sci Med. 2008;67(3):420-430. doi:10.1016/j.socscimed.2008.03.010

18. Maurer J, Rebbapragada V, Borson S, et al. Anxiety and depression in COPD: current understanding, unanswered questions, and research needs. Chest. 2008;134(Suppl 4):43-56. doi:10.1378/chest.08-0342

19. Menezes AM, Landis SH, Han MK, et al. Continuing to confront COPD International Surveys: comparison of patient and physician perceptions about COPD risk and management. Int J Chron Obstruct Pulmon Dis. 2015;10:159-172. doi:10.2147/COPD.S74315

20. Johnson JL, Campbell AC, Bowers M, Nichol AM. Understanding the social consequences of chronic obstructive pulmonary disease: the effects of stigma and gender. Proc Am Thorac Soc. 2007;4 (8):680-682. doi:10.1513/pats.200706-084SD

21. Celli B, Blasi F, Gaga M, et al. Perception of symptoms and quality of life comparison of patients' and physicians' views in the COPD MIRROR study. Int J Chron Obstruct Pulmon Dis. 2017;12:2189-2196. doi:10.2147/COPD.S136711

22. Van Eerd EAM, Bech Risør M, Spigt M, et al. Why do physicians lack engagement with smoking cessation treatment in their COPD patients? A multinational qualitative study. NPJ Prim Care Respir Med. 2017;27(1):41. doi:10.1038/s41533-017-0038-6

23. Banfi P, Cappuccio A, Latella M, Reale L, Muscianisi E, Marini M. Narrative medicine to improve the management and quality of life of patients with COPD: the first experience applying parallel chart in Italy. Int J Chron Obstruct Pulmon Dis. 2018;13:287-297. doi: $10.2147 / \mathrm{COPD}$

24. West R. The multiple facets of cigarette addiction and what they mean for encouraging and helping smokers to stop. COPD. 2009;6 (4):277-283. doi:10.1080/15412550903049181

25. West R. Tobacco smoking: health impact, prevalence, correlates and interventions. Psychol Health. 2017;32(8):1018-1036. doi:10.1080/ 08870446.2017.1325890

26. Vink JM, Willemsen G, Boomsma DI. Heritability of smoking initiation and nicotine dependence. Behav Genet. 2005;35(4):397-406. doi:10.1007/s10519-004-1327-8

27. van Schilfgaarde R, Willems E, Bottema J, et al. [Healthcare module smoking cessation]. Zorgmodule Stoppen Met Roken. 2009. Available from: http://www.partnershipstopmetroken.nl/wp-content/uploads/2013/ 01/ZorgmoduleStoppenmetRoken_PartnershipStopmetRoken_2009.pdf. Accessed December 8, 2018. Dutch.

28. van Eerd EA, Risør MB, van Rossem CR, van Schayck OC, Kotz D. Experiences of tobacco smoking and quitting in smokers with and without chronic obstructive pulmonary disease-a qualitative analysis. BMC Fam Pract. 2015;16:164. 
29. Willems RA, Willemsen MC, Smit ES, Nagelhout GE, Janssen E, de Vries H. Which smoking cessation aids are proven effective according to smokers who want to quit smoking? A report from the Netherlands. Tob Control. 2014;23(6):525-526. doi:10.1136/tobaccocontrol-2013-051076

30. Stead LF, Buitrago D, Preciado N, Sanchez G, Hartmann-Boyce J, Lancaster T. Physician advice for smoking cessation. Cochrane Database Syst Rev. 2013;(5):CD000165.

31. Aveyard P, Begh R, Parsons A, West R. Brief opportunistic smoking cessation interventions: a systematic review and meta-analysis to compare advice to quit and offer of assistance. Addiction. 2012;107 (6):1066-1073. doi:10.1111/add.2012.107.issue-6
32. Eklund BM, Nilsson S, Hedman L, Lindberg I. Why do smokers diagnosed with COPD not quit smoking? - a qualitative study. Tob Induc Dis. 2012;10(1):17. doi:10.1186/1617-9625-10-17

33. Lindson-Hawley N, Thompson TP, Begh R. Motivational interviewing for smoking cessation. Cochrane Database Syst Rev. 2015;2(3): CD006936.

34. Mevius L, van Eijsden P. [Smoking, the perfect crime]. Roken, de perfecte misdaad. Ned Tijdschr Geneeskd. 2017;161:C3732.

\section{Publish your work in this journal}

The International Journal of COPD is an international, peer-reviewed journal of therapeutics and pharmacology focusing on concise rapid reporting of clinical studies and reviews in COPD. Special focus is given to the pathophysiological processes underlying the disease, intervention programs, patient focused education, and self management protocols. This journal is indexed on PubMed Central, MedLine and CAS. The manuscript management system is completely online and includes a very quick and fair peer-review system, which is all easy to use. Visit http://www.dovepress.com/testimonials.php to read real quotes from published authors. 